\title{
Effect of Swim Suit Design on Passive Drag
}

\author{
JOSEPH C. MOLLENDORF ${ }^{1-3}$, ALBERT C. TERMIN II ${ }^{4}$, ERIC OPPENHEIM ${ }^{2}$, and DAVID R. PENDERGAST ${ }^{1,3}$ \\ ${ }^{1}$ Center for Research and Education in Special Environments; ${ }^{2}$ Department of Mechanical \& Aerospace Engineering, \\ School of Engineering and Applied Sciences; ${ }^{3}$ Department of Physiology and Biophysics, School of Medicine and \\ Biomedical Sciences; and ${ }^{4}$ Division of Athletics, University at Buffalo, Buffalo, NY
}

\begin{abstract}
MOLLENDORF, J. C., A. C. TERMIN II, E. OPPENHEIM, and D. R. PENDERGAST. Effect of Swim Suit Design on Passive Drag. Med. Sci. Sports Exerc., Vol. 36, No. 6, pp. 1029-1035, 2004. Introduction: The drag (D) of seven (7) male swimmers wearing five (5) swimsuits was investigated. Methods: The drag was measured during passive surface tows at speeds from 0.2 up to $2.2 \mathrm{~m} \cdot \mathrm{s}^{-1}$ and during starts and push-offs. The swimsuits varied in body coverage from shoulder-to-ankle (SA), shoulder-to-knee (SK), waist-to-ankle (WA) and waist-to-knee (WK) and briefs (CS). Results: Differences in total drag among the suits were small, but significant. In terms of least drag at $2.2 \mathrm{~m} \cdot \mathrm{s}^{-1}$, the swimsuits ranked: SK, SA, WA, WK and CS. The drag was decomposed into its pressure drag $\left(D_{\mathrm{P}}\right)$, skin friction drag $\left(D_{S F}\right)$ and wave drag $\left(D_{W}\right)$ components using nonlinear regression and classical formulations for each drag component. The transition-to-turbulence Reynolds number and decreasing frontal area with speed were taken into account. The transition-to-turbulence Reynolds number location was found to be very close to the swimmers' "leading edge," i.e. the head. Flow was neither completely laminar, nor completely turbulent; but rather, it was transitional over most of the body. The $\mathrm{D}_{\mathrm{P}}$ contributed the most to drag at low speeds $\left(<1.0 \mathrm{~m} \cdot \mathrm{s}^{-1}\right)$ and $\mathrm{D}_{\mathrm{W}}$ the least at all speeds. $\mathrm{D}_{\mathrm{SF}}$ contributed the most at higher speeds for SA and SK suits, whereas $D_{P}$ and $D_{W}$ were reduced compared with the other suits. Conclusion: The decomposition of swimmer drag into $D_{S F}, D_{P}$ and $D_{W}$ suggests that increasing $D_{S F}$ on the upper-body of a swimmer reduces $D_{P}$ and $D_{W}$ by tripping the boundary layer and attaching the flow to the body from the shoulder to the knees. It is possible that body suits that cover the torso and legs may reduce drag and improve performance of swimmers. Key Words: FRICTION DRAG, PASSIVE DRAG, WAVE DRAG, TURBULENT FLOW, LAMINAR FLOW
\end{abstract}

$\mathrm{S}$ wimming performance is measured to the nearest $0.01 \mathrm{~s}$, with swimmers in the top 16 of meets separated by only $0.10 \mathrm{~s}$. Because drag is a major factor in the energetics of swimming, small decreases in the swimmer's drag can affect performance. With the availability of a new generation of suits that cover larger parts of the body and are made of different materials than the traditional suits, there is a potential for drag reduction. These new suits are reported, in a nonrefereed swim magazine, to reduce skin friction of the material itself (without a swimmer) by $16 \%$ and by $10 \%$ when worn by a swimmer (17). A Lycra specially designed suit covering the torso of male swimmers reduced the energy demand of swimming, compared with a standard racing suit, presumably due to the drag-reducing characteristic of the suit (14). The opinion that these new suits improve performance is, however, not universally accepted. It was concluded (based on active drag measurements and a statistical analysis of performance times), in

another nonrefereed swim magazine (11) that these types of suits do not reduce drag or improve performance.

It is well known that surface characteristics have an effect on fluid mechanical drag. In general, the effect of uniformly distributed surface roughness is to decrease the transitionto-turbulence Reynolds number. This will increase skinfriction drag because turbulent skin-friction drag is higher than laminar skin-friction drag. The same is true for single protuberances with height a fraction of the boundary layer thickness. Surface roughness and protuberances may alter transition-to-turbulence on the swimmer, and may attenuate overall drag.

The purpose of this study was to combine theoretical models with passive drag measurements to determine whether these new generation suits are drag reducing, and if so, what the physical mechanisms behind the reduction are. Passive drag was used to concentrate on the effects of the suit alone, and not the swimmer technique or style.

Address for correspondence: Joseph C. Mollendorf, Ph.D., Center for
Research and Education in Special Environments, 124 Sherman Hall,
University at Buffalo, Buffalo, NY 14214; E-mail: molendrf@ buffalo.edu.
Submitted for publication February 2003.
Accepted for publication February 2004.

0195-9131/04/3606-1029

MEDICINE \& SCIENCE IN SPORTS \& EXERCISE E $_{\circledast}$

Copyright (C) 2004 by the American College of Sports Medicine

DOI: 10.1249/01.MSS.0000128179.02306.57

\section{METHODS}

Seven male University Division I swimmers participated in this study. They average $20.2 \pm 0.5 \mathrm{yr}$ of age, $171 \pm 12$ $\mathrm{cm}$ in height, $71.80 \pm 1.66 \mathrm{~kg}$ in weight, $51.3 \pm 0.9 \mathrm{~cm}$ in chest width, $25.4 \pm 0.4 \mathrm{~cm}$ in chest depth, and $8 \pm 1 \%$ body fat. The study was approved by the University's Institutional Review Board; subjects completed a medical history, were given a physical examination, and completed an informed consent form. 
Four swimsuits that covered various body surface areas (Fastskin by Speedo) and a traditional competition suit (Speedo) were purchased commercially for each swimmer, and their drags were determined and compared. These suits also represented the suits most commonly purchased by competitive swimmers (personal communication from Adolph Kiefer and associates). The body surface areas covered were shoulder-to-ankle (SA), shoulder-to-knee (SK), waist-to-ankle (WA), and waist-to-knee (WK). The suits were made of microfiber polyester and Lycra material. All testing was done with the suits initially dry, and the order of the suits in testing was randomly assigned for each swimmer. All of the swimmers wore a conventional swimming cap.

The densities of the swimsuits were determined using standard densitometric techniques. The suits, when dry, were weighed in air and then placed into a press device to eliminate any air, and then were weighed in water while still in the press. This technique was repeated with the suits after they were immersed in water (while wet) by the same techniques.

\section{Measured Towing Drag}

Two sets of drag measurements were taken, passive towing at the surface in an annular pool $58.6 \mathrm{~m}$ in circumference, over the path of the swimmer, and $2.5-\mathrm{m}$ wide and 2.5-m deep and during starts and turns in a standard Olympic pool. Both starts and turns were considered separately, because the initial speeds of each are different and the starts involve motion in air and water. The pool temperatures were maintained at $28^{\circ} \mathrm{C} \pm 0.2^{\circ} \mathrm{C}$ with the air temperature at $22^{\circ} \mathrm{C} \pm 2.0^{\circ} \mathrm{C}$.

For the towing experiments, the swimmers were towed passively at the water surface. The swimmer held onto a handle that was attached by a wire through pulleys to a vertically mounted dynamometer (Model TDC 4A, Schaevitiz Engineering, Pennsauken, NJ) that was fixed to a monitoring platform that towed the swimmer. The platform speed was set by a calibrated impeller flow meter (Model HP301A2M, Mead Instruments, Riverdale, NJ). The velocities started at $0.2 \mathrm{~m} \cdot \mathrm{s}^{-1}$ and were increased in $0.2 \mathrm{~m} \cdot \mathrm{s}^{-1}$ increments up to $2.2 \mathrm{~m} \cdot \mathrm{s}^{-1}\left( \pm 0.03 \mathrm{~m} \cdot \mathrm{s}^{-1}\right.$, over the entire speed range).

Swimmers breathed through a swimmer's snorkel (Finis Inc., Tracy, CA) and force (total drag; D) was measured using the vertically mounted dynamometer, the output of which was conditioned using a Linear Variable Differential Transformer (Model 300D, Daytronics, Dayton, OH). The output of the LVDT was processed using an A/D Converter (Model PPIO-AI08, ComputerBoards, Mansfield, MA) via software developed "in house" to average and store velocity and force every min using a personal computer (Model 770, IBM Thinkpad, Armonk, NY). The data were then plotted as a function of velocity. All devices were calibrated before and after each experiment.

During the passive towing experiments, the swimmers (and a calibration frame) were videotaped through an un- derwater window using a video camera (DCR TRV 840, Sony, Oradell, NJ). A simple vertical and horizontal linear scale was used as a camera calibration frame. After each swim, the video was replayed and the frontal area, $\mathrm{A}_{\mathrm{f}}(\theta)$, of the swimmer was calculated from the whole body angle, $\theta$, from the horizontal (averaged over the body length) using the following equation:

$$
\mathrm{A}_{\mathrm{f}}(\theta)=\left(\mathrm{A}_{\mathrm{f} 0}\right) \cos \theta+\left(\mathrm{A}_{\mathrm{S}} / 2\right) \sin \theta
$$

where $\mathrm{A}_{\mathrm{fO}}$ is the frontal area when the swimmer is horizontal $(\theta=0)$ and $\mathrm{A}_{\mathrm{s}}$ is the body surface area. The measured angle represents a time average and was assumed to not vary with suit design.

\section{Measured Glide Drag}

For the starts and push-offs experiments, the coefficient of drag was determined in a competitive swimming pool after a push-off from the wall or after a dive from the starting blocks using a device called a "swim-meter" developed by Craig and Pendergast (3). The swim-meter measured the decrease in instantaneous velocity as the subject decelerated passively from the maximal initial velocity. The swim-meter consisted of a wire secured to the swimmer that passed through a system of pulleys and turned a DC generator (3) as the wire was pulled from a fishing reel. The output of the DC generator was recorded using a computer and the drag coefficient $\left(\mathrm{C}_{\mathrm{D}}\right)$ was calculated using a method based on a linear mass-damper system. As such, the drag force is assumed to be the sum of a linear and quadratic function of the velocity. The constants of proportionality are determined from the results of a regression of the measured transient velocity data. Additional details are given in the thesis, Oppenheim, E. Model parameter and drag coefficient estimation from swimmer velocity measurements (M.S. Thesis, Department of Mechanical Engineering, University at Buffalo, 1997).

\section{Theoretical Calculations}

Data analysis. For surface swimming, the most relevant kinds of drag are skin-friction drag, pressure drag and wave and spray drag. A passively towed swimmer's surface can be approximated by an arrangement of a sphere and circular cylinders in axial flow. Because the boundary layers are typically thin compared with the radii, the flows can be modeled to a good approximation as flows over flat plates $(2,6,8)$.

The Reynolds number, $\mathrm{Re}_{\mathrm{L}}$, based on a characteristic length, $\mathrm{L}$, is defined as, $\mathrm{Re}_{\mathrm{L}}=\mathrm{V} \mathrm{L} / \nu$, where $\mathrm{V}$ is the swimming speed and $\nu$ is the fluid kinematic viscosity. For high Reynolds numbers, as observed in competitive swimming, the flow experiences transition-to-turbulence, separates from the surface, and the pressure drag is caused by viscosity.

For flow over a flat plate at zero angle-of-attack, transition-to-turbulence begins at about $\mathrm{Re}_{\mathrm{L}}=5 \times 10^{5}$ and ends at about $\operatorname{Re}_{\mathrm{L}}=10^{7}(7)$. For a swimmer $170 \mathrm{~cm}$ tall, the Reynolds numbers based on swimmer length (height) corresponding to $\mathrm{V}=0.3 \mathrm{~m} \cdot \mathrm{s}^{-1}$ and $2.2 \mathrm{~m} \cdot \mathrm{s}^{-1}$ are $5.10 \times 10^{5}$ 
and $3.74 \times 10^{6}$, respectively. Consequently, the flow over the length of the swimmer's body is neither completely laminar nor completely turbulent, it is transitional and illdefined. For example, in a completely "still" ambient, freestream turbulence will be absent and transitional flows can persist as laminar beyond about, $\mathrm{Re}_{\mathrm{cr}}=5 \times 10^{5}$. On the other hand, in a "noisy" ambient, both the beginning and end of transition-to-turbulence will occur at lower Reynolds numbers. That is to say, the flow is "trippable" (to turbulence).

As a result, the forward portion of the swimmer, modeled as a flat plate, will be in laminar flow, and most of the aft portion of the swimmer will be in transitional flow. It is important to note that in the present study the length of the swimmer is defined as the swimmer height. Thus, for a general scenario, laminar, transition and turbulent flow regime limits can be described in terms of swimmer speed and swimmer height. For example, it can be seen from Figure 1 that for a speed of $2 \mathrm{~m} \cdot \mathrm{s}^{-1}$, the laminar flow ends at about $25 \mathrm{~cm}$ aft of the swimmer's head and that most of the body of the swimmer is in the near-laminar/transition-to-turbulence region. For the towing procedure used in the present study, the swimmer's arms are outstretched as indicated on Figure 2. It seems reasonable (as was assumed here) that the outstretched arms are quite streamlined and they do not significantly disturb the flow or contribute to drag. The head, followed by the shoulders, represents the "leading edge" of the main part of the body. In this sense, the outstretched arms can be thought of as an extension of the towing cable. The actual extent of the laminar flow region depends upon both swimming speed and the transition-toturbulence Reynolds number. The latter is determined as

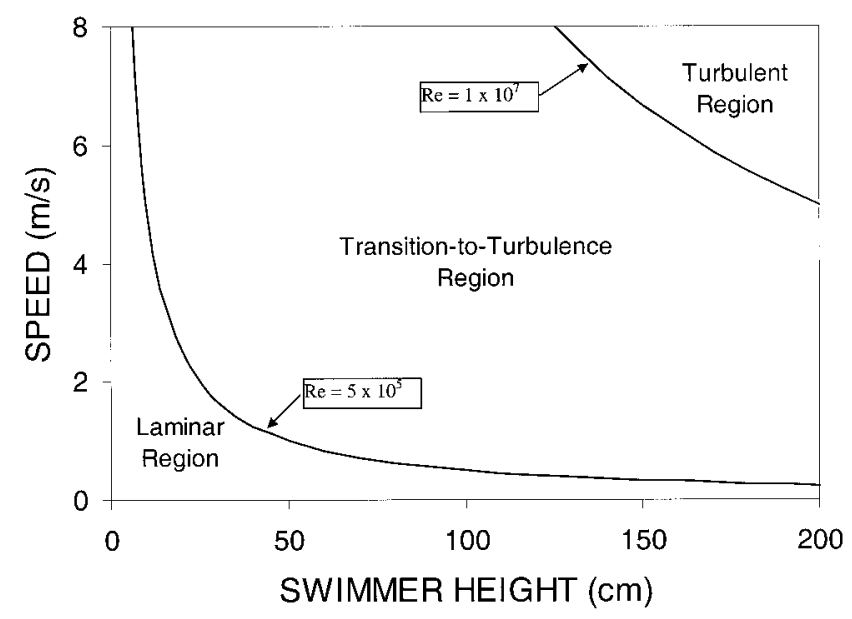

FIGURE 1-Speed is plotted as a function of the height a hypothetical average swimmer if transition-to-turbulence began at a $\operatorname{Re}$ of $5 \times 10^{5}$ and ended at $1 \times 10^{7}$. The region between the laminar flow and turbulent flow regions is the transition-to-turbulence region $(25 \mathrm{~cm}$ and beyond, for a swimming speed of $2.2 \mathrm{~m} \cdot \mathrm{s}^{-1}$ ). For this hypothetical plot, the laminar region is less than $25 \mathrm{~cm}$ from the top of the head for a swimming speed of $2.2 \mathrm{~m} \cdot \mathrm{s}^{-1}$. The more turbulent region is from the knee to the foot, with the region between the head and knee in the early transition region. The data reported herein suggest that transition-toturbulence begins at a Reynolds number considerably less than $5 \times 10^{5}$. one of the fit parameters in our regression of the data reported herein.

The skin-friction drag of the swimmer, $\mathrm{D}_{\mathrm{SF}}$, was calculated as for a flat plate in the transition-to-turbulence region (7) as:

$$
\mathrm{D}_{\mathrm{SF}}=\mathrm{q} \mathrm{A} \mathrm{A}_{\mathrm{S}}\left[0.074 / \mathrm{Re}_{\mathrm{L}}{ }^{1 / 5}-1740 / \mathrm{Re}_{\mathrm{L}}\right]
$$

where $\mathrm{q}$ is the dynamic pressure, $\mathrm{q}=1 / 2 \rho \mathrm{V}^{2}, \rho$ is the fluid density, and $A_{S}$ is the surface area. The corresponding pressure drag $\left(D_{P}\right)$ was calculated using the results of Schmitt (12). As a starting point in the data regression, the skin friction drag was calculated using one half $(1 / 2)$ of the body surface area, because it is assumed that the swimmer would be partially out of the water. The actual body surface area is not needed, however, because it is "buried" in the regression coefficient. This can be seen in the equation for $\mathrm{D}_{\mathrm{SF}}$ on Figure 2. The $\mathrm{D}_{\mathrm{P}}$ was formulated to be proportional to the second power of the velocity and directly proportional to the frontal surface area, which is a measured function of the body angle variation with speed. The $\mathrm{D}_{\mathrm{W}}$ was formulated to be proportional to the fourth power of the velocity. Thus, the experimental data were used as the basis for the theoretical calculations. Drag decomposition consisted of summing the drag components and then determining the proportionality constants as well as the transition Reynolds number using a standard multiple, nonlinear regression package (NonlinearFit, Mathematica, Wolfram Research).

\section{Statistical Analysis}

Mean and SD were calculated for all data to describe and present the individual values in the figures and tables. The data for the different suits were compared using an ANOVA for repeated measures for suits and speeds. Data were also fit, using regression analysis, with the best statistical fit being reported. The 0.05 level of significance was accepted for all comparisons.

\section{RESULTS}

Complete drag and drag coefficient data were obtained on the seven swimmers in the five suits. The suit weights in air ranged from 0.32 to $0.34 \mathrm{~kg}$, and the densities ranged from 1.0536 to 1.0883 both wet and dry. All of the suits tested had a density greater than water, and there were no significant differences among the suits tested.

Measured towing drag. The test-retest reliability of the passive drag measurement (Fig. 2) was $0.94(N=77)$. The regression analysis allowed the value of the critical Reynolds number to "float" and be a parameter to be determined by the behavior of the data. As such, it was found that transition-to-turbulence occurred at a $\mathrm{Re}$ of about $3 \times$ $10^{3}$ (lowest curve, lower left corner of Fig. 2, left panel). It can be seen that the transition from laminar flow occurs very early (a few centimeters), i.e., near the maximal diameter of the head, and was not significantly different among the suits tested (Fig. 2, left panel). Therefore, most of the length of 

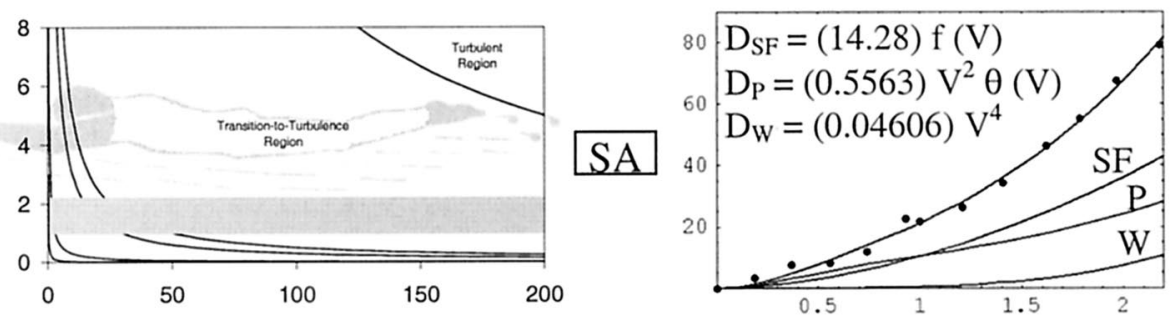

FIGURE 2-Data for total drag and drag decomposed into drag due to skin frictional $\left(\mathrm{D}_{\mathrm{SF}}\right)$, drag due to pressure $\left(D_{P}\right)$ and drag due to wave $\left(D_{W}\right)$ are shown as a function of velocity in the right panels for the five tested suits in order (from top to bottom) of decreasing total drag. The left panels show the suit coverage areas as well as swimming speed plotted as a function of the swimmer's height. The shaded area indicates the speeds observed in competitive swimming. All values are the averages of the seven subjects tested. The three curves in the lower left corner of the left panel are for transition Reynolds numbers: $3 \times 10^{3}, 3 \times 10^{4}$, and 3 $\times 10^{5}$. The other two curves are the same as those in Figure 1; namely, $5 \times$ $10^{5}$ and $1 \times 10^{7}$. The left panel shows that the laminar flow region persists within only the first few centimeters of the head for the transition Reynolds numbers shown, whereas the region between the head and knee has transitional flow. The data for the $\mathrm{D}_{\mathrm{SF}}, \mathrm{D}_{\mathrm{P}}$, and $D_{w}$ are shown for each suit in the right panel along with the equations that describe the data. The $\mathrm{D}_{\mathrm{SF}}$ was significantly greater for the SA and SK suits than the WA, WK, and competition suit, whereas the $D_{P}$ and $D_{W}$ were significantly lower, as was the total $\mathrm{D}$. There was not a statistically significant difference between the SA and SK suits.
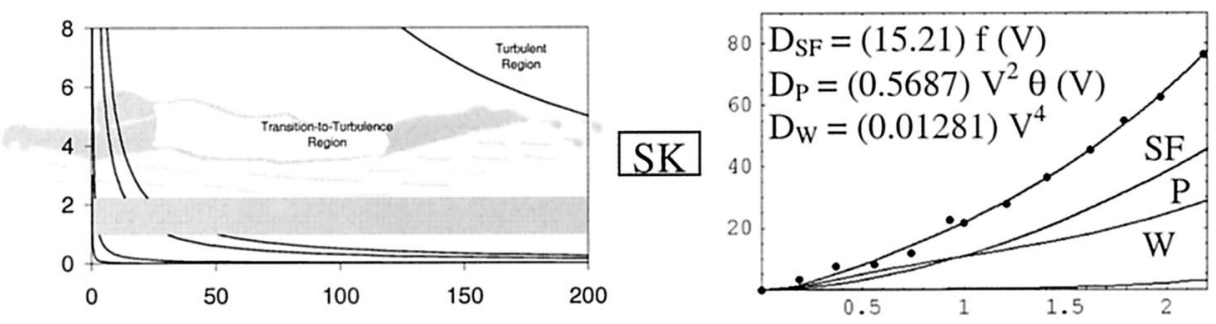
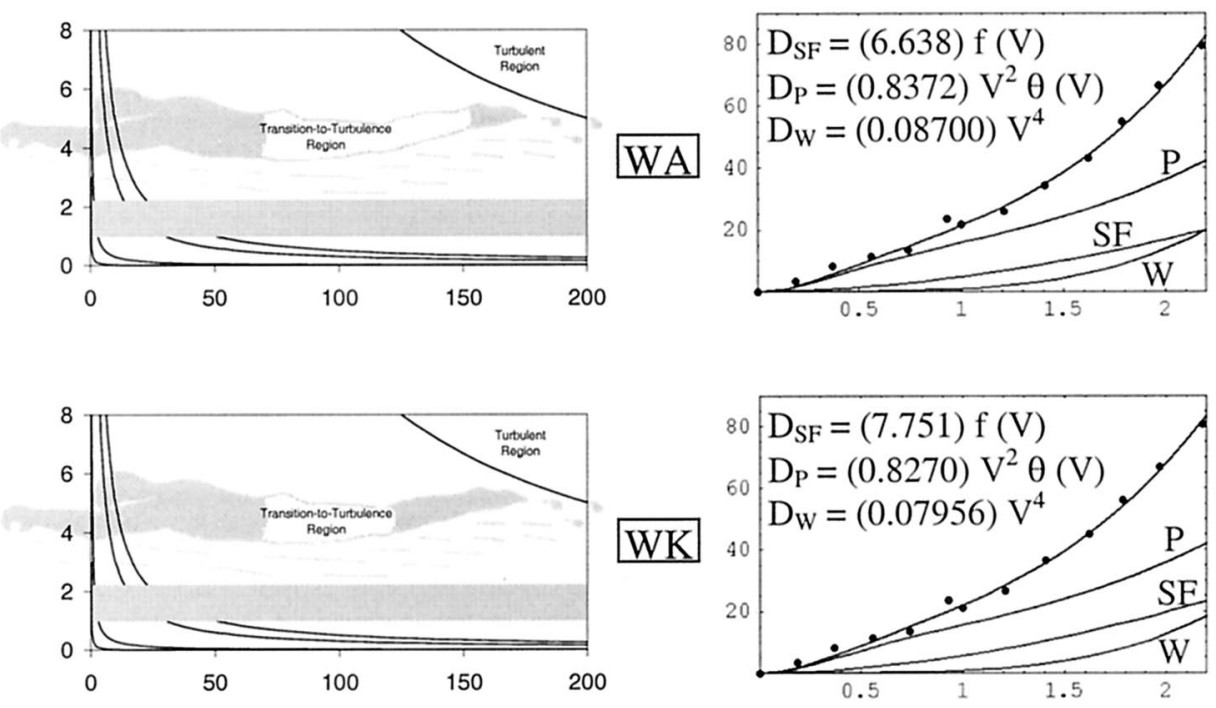

SPEED $(\mathrm{m} / \mathrm{s})$

DRAG (N)
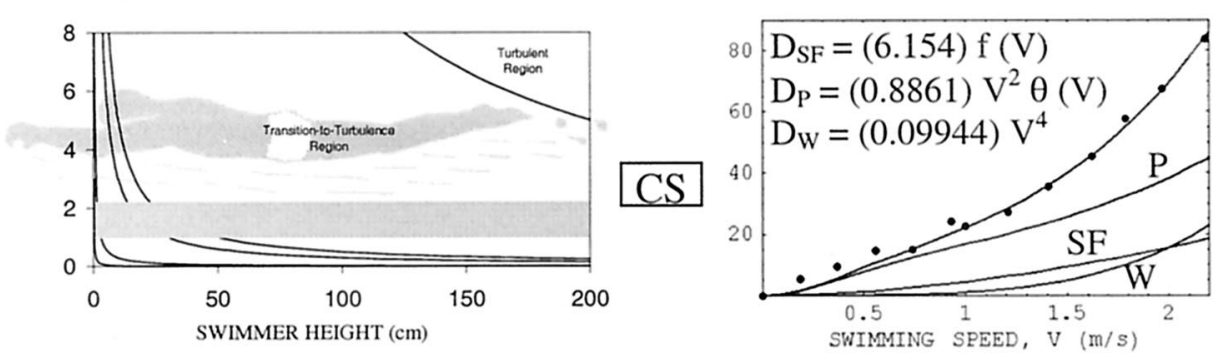

the body, between the head and feet, is in the transition phase.

The total drag increased monotonically: $77.5 \pm 3.7,81.7$ $\pm 3.9,82.3 \pm 4.8,83.5 \pm 4.9$, and $86.2 \pm 4.3 \mathrm{~N}$ at a $\mathrm{V}$ of $2.2 \mathrm{~m} \cdot \mathrm{s}^{-1}$, for the SK, SA, WA, WK and CS, respectively (Fig. 2, right panel). From these data, it can be concluded that the more surface area of the torso that is covered with the Fastskin suit material the less the total drag was and ranged from $3 \%$ for $\mathrm{WK}$ to $10 \%$ for $\mathrm{SK}$.

Measured glide drag. As described in the method section, the $C_{D}$ was calculated from both dives and push- offs (Table 1). The test-retest reliability of the $\mathrm{C}_{\mathrm{D}}$ was 0.978 $(N=35)$.

The peak velocities achieved were not significantly different among the suits for the starts or turns and were 5.829 $\pm 0.128 \mathrm{~m} \cdot \mathrm{s}^{-1}$ for the starts and $2.68 \pm 0.07 \mathrm{~m} \cdot \mathrm{s}^{-1}$ for the push-offs. The $\mathrm{C}_{\mathrm{D}}$ for $\mathrm{SA}, \mathrm{SK}, \mathrm{WA}$, and WK were not statistically different from each other, but all were significantly different from CS (15, 8, 8, and 10\%, respectively).

Theoretical calculations. Decomposing the total drag yielded expressions for $\mathrm{D}_{\mathrm{SF}}, \mathrm{D}_{\mathrm{P}}$, and $\mathrm{D}_{\mathrm{W}}$ (Fig. 2, right panel). $\mathrm{D}_{\mathrm{SF}}$ increased as function of $\mathrm{V}$ and was significantly 
TABLE 1. The mean and SD values for the coefficient of drag, $C_{D}=($ drag force $) /(1 / 2$ $\rho \mathrm{V}^{2} A_{S}$ ), determined from the deceleration during a dive and push-off for the five suits tested.

\begin{tabular}{cccccc}
\hline Suit & SA & SK & WA & WK & CS \\
\hline Mean & $0.832^{\star}$ & $0.897^{\star}$ & $0.896^{\star}$ & $0.880^{\star}$ & 0.978 \\
SD & 0.043 & 0.079 & 0.081 & 0.063 & 0.074 \\
\hline
\end{tabular}

* Significant difference from the competition suit (CS).

greater in the SA and SK suits $(42.8$ and $45.6 \mathrm{~N}$, respectively, at $\left.\mathrm{V}=2.2 \mathrm{~m} \cdot \mathrm{s}^{-1}\right)$ than the WA, WK, and CS (20.0, 23.3 , and $18.5 \mathrm{~N}$, respectively, at $\mathrm{V}=2.2 \mathrm{~m} \cdot \mathrm{s}^{-1}$ ), which were not significantly different from each other. $D_{P}$ increased as a function of $\mathrm{V}^{2}$ and was significantly lower in SA and SK (28.3 and $28.9 \mathrm{~N}$, respectively, at $\mathrm{V}=2.2$ $\left.\mathrm{m} \cdot \mathrm{s}^{-1}\right)$ than in WA, WK, and CS $(42.4,41.9$, and $44.9 \mathrm{~N}$, respectively, at $\mathrm{V}=2.2 \mathrm{~m} \cdot \mathrm{s}^{-1}$ ), which were not significantly different from each other. $\mathrm{D}_{\mathrm{W}}$ increased as a function of $\mathrm{V}^{4}$, and the SA and SK suits values were significantly lower (10.6 and $3.0 \mathrm{~N}$, respectively, at $\left.\mathrm{V}=2.2 \mathrm{~m} \cdot \mathrm{s}^{-1}\right)$, than the WA, WK, and CS $(19.9,18.3,22.8 \mathrm{~N}$, respectively, at V $=2.2 \mathrm{~m} \cdot \mathrm{s}^{-1}$ ), which were not significantly different from each other. In summary the higher $\mathrm{D}_{\mathrm{SF}}$ in the SA and SK suits resulted in a reduction in both the $D_{P}$ and $D_{W}$, which was not observed for the WA or WK suits. Covering the torso increased the $\mathrm{D}_{\mathrm{SF}}$, which presumably reduced the $\mathrm{D}_{\mathrm{P}}$ and $\mathrm{D}_{\mathrm{W}}$ by tripping the boundary layer and attaching flow to the remainder of the body. The absence of significant differences between SA and SK (one comparison), and WA and WK (another comparison) for $\mathrm{D}_{\mathrm{SF}}, \mathrm{D}_{\mathrm{P}}$, and $\mathrm{D}_{\mathrm{W}}$ may reside in the observation that flow below the knee is becoming turbulent (Fig. 2, left panel) and thus covering this area does not alter drag. It is tentatively concluded that the lower $\mathrm{D}_{\mathrm{W}}$ for SK may be due to the absence of coverage from the knee to the ankle. This effect is apparently counteracted by the increase in $\mathrm{D}_{\mathrm{P}}$ for $\mathrm{WA}, \mathrm{WK}$, and CS due to the absence of coverage from the shoulder to the waist. Accordingly, coverage from the shoulder to the waist trips the boundary layer and promotes attached flow, hence lowering $D_{P}$.

\section{DISCUSSION}

Swimming performance is determined, in part, by the body drag of the swimmer, which has components of friction, pressure, and wave. The relative importance of these three sources of drag is velocity dependent; thus, to understand the contribution of these sources of drag in competitive swimming, velocities of $1.5-2.2 \mathrm{~m} \cdot \mathrm{s}^{-1}$ must be evaluated.

Previous studies have shown that the energy requirement of swimming at all speeds is determined, in part, by the individual swimmer's body density and torque $(1,9,10,18,19)$. Although these factors are set by the stature of the swimmer, decreasing his density could lower drag and/or energy requirement $(11,18,19)$. This has been shown for a wet suit $(15)$. The five suits tested in this study had densities slightly greater than water, and thus would not significantly alter body density. In this study, the swimmers squeezed-out any air that might have been trapped between their body and the suit using their hands
This was done because trapped air could affect body density during competition (11).

Theoretically, based upon basic fluid mechanics, the way to reduce the drag of a swimmer at the surface is to: 1) reduce the wetted surface area, 2) promote laminar flow over the surface, 3 ) promote attached flow, and 4) minimize the production of waves and spray. One potential method to accomplish drag reduction is to wear drag-reducing suits. These suits have been purported to reduce skin friction $(11,17)$, although it should be cautioned that these references are nonrefereed swim magazines. However, the results of a scientific study (16) also suggest a reduction in drag, although the reduction was not statistically significant. It should be noted that laminar flow and attached flow are distinctly independent concepts arising from basic fluid mechanics. Further, attached turbulent flow typically has higher skin friction drag but lower pressure drag than detached (separated) laminar flow. It is this trade-off between the skin friction, pressure and wave drag that suggested the need for the presently reported study.

It is commonly held that drag-reducing suits reduce $\mathrm{D}_{\mathrm{SF}}$ $(10-15 \%)$ (17); however, $\mathrm{D}_{\mathrm{SF}}$ is low in swimming $(11,17,20)$. Consequently, an alteration in $\mathrm{D}_{\mathrm{SF}}$ was previously believed to hold little promise for drag reduction. Furthermore, before the presently reported study, the quantitative details of the trade-offs between the various kinds of drag were unknown. A comparison with previously reported drag breakdown indicates that the pressure drag, $D_{P}=93.5$ $\mathrm{N}(20)$, is about 2-3 times greater than that reported here. The skin friction drag, $\mathrm{D}_{\mathrm{SF}}=0.05 \mathrm{~N}(20)$, is approximately 400-900 times smaller than that reported here. The wave drag, $D_{\mathrm{w}}=5 \mathrm{~N}(20)$, is about four times smaller than that reported here. It appears, however, that (20) used the Newtonian definition of viscosity and the relationship between surface shear and time-rate-of-change of strain for a Newtonian fluid for friction resistance. As such, $\mathrm{dV} / \mathrm{dZ}$ is meant to represent the slope of the velocity profile at the surface, not a finite difference approximation to the average slope. Using the average slope (20) will result in a very significant underestimate of friction resistance because the velocity distribution (and hence its slope) is increasing rapidly near the surface to accommodate the no-slip boundary condition at the surface. Further, no basis is given for the ranges of input parameters and one input parameter value used was not in the range given. Finally, it appears that there are errors in units and in the numerically computed values. Our work does not rely on guessing from a range of parameters but, rather, uses appropriate theoretical formulations and lets the data (based on measurements) determine the relative coefficients based on the best fit in a least squares sense. In the present study, $\mathrm{D}_{\mathrm{SF}}$ was not reduced by the suits tested; in fact, $\mathrm{D}_{\mathrm{SF}}$ was higher in the SA and SK suits than the WA, WK, or CS. The density of the swimmer was not affected by the suits tested; thus, it is unlikely that the wetted surface area of the swimmer is reduced. The laminar flow region of the swimmers among all suits tested were not significantly different (Fig. 1, left column), and transition-to-turbulence 
occurred at the head, before the areas of the body covered by any of the suits.

There was significant drag reduction (10-15\%) when the swimmers wore the SA or SK suits compared with the other suits (Fig. 2, right panel). There was not a statistically significant difference between the SA and SK suits. The reduction in total drag occurred, in spite of the observation that $\mathrm{D}_{\mathrm{SF}}$ increased by twofold, due to the reduction in $\mathrm{D}_{\mathrm{P}}(37 \%)$ and $\mathrm{D}_{\mathrm{W}}$ $(60-80 \%)$. These data support the conclusion that the increased $\mathrm{D}_{\mathrm{SF}}$ tripped the boundary layer and that the flow remained attached to the body past the shoulders, in the transitional phase, and thus lowered both $\mathrm{D}_{\mathrm{P}}$ and $\mathrm{D}_{\mathrm{W}}$.

The absence of significant drag reduction with dragreducing suits that start their coverage at the waist implies that these suits did not lower $\mathrm{D}_{\mathrm{SF}}$ or trip the boundary layer, or if they did, the effects were not significant. This finding is interesting because the lower body coverage suits are the most commonly ordered men's suits. It is noted that the measured glide data in Table 1 indicates that the "leg-only" body suits (WK and WA) showed a significant reduction in drag compared with the conventional suit (CS). Further from Table 1, the SA and SK suits were not significantly different from each other. On the other hand, using the measured towing data the SA and SK suits were significantly different from the WA, WK, and CS suits. We believe that the accuracy of the measured towing data is better than the accuracy of the measured glide data because the towing data were taken over a much longer time period (more than 5 min per speed) whereas the measured glide data relied on a data fit over a short time (a few seconds per glide).

The data from this study also demonstrate that the coverage of the leg below the knee is not essential to the drag reduction of the suits (SK and WK were as effective as SA and WA). The calf may be in the region of turbulent flow and thus the boundary layer can not be tripped or this area is too small to have an effect. Table 1 shows that the SA, SK, WA, and WK suits exhibited significant difference from the CS suit (only), not between the SA, SK, WA, and WK suits. As stated earlier, a more accurate discriminator is the measured towing data, for the reasons given above.

It should be noted that the observation that the laminar flow is disrupted at the head suggests that tripping the boundary layer at the head gives the greatest reduction in drag. It should also be considered that tripping the boundary layer at multiple locations may be required as flow separation may occur at all parts of the body were there are marked changes in curvature (head, shoulders, buttocks).

An alternative method to reduce drag would be to place protuberances (vortex generators) at strategic places on the swimmer. Some models of these suits with protuberances have been developed and tested and have been shown to reduce drag, with $2.5-\mathrm{mm}$ protuberances being recommended $(11,17)$. A prototype suit with $10-\mathrm{mm}$ protuberances at the buttocks was tested on six swimmers and was not found to reduce $\operatorname{drag}\left(\mathrm{C}_{\mathrm{D}}\right.$ of $\left.0.846 \pm 0.119\right)$ when compared with a similar suit without protuberances $\left(\mathrm{C}_{\mathrm{D}}\right.$ $0.869 \pm 0.203)$; however, both suits were lower than a competition suit $(0.902 \pm 0.115)$. Additional details are given in the thesis, Oppenheim, E. Model parameter and drag coefficient estimation from swimmer velocity measurements (M.S. Thesis, Department of Mechanical Engineering, University at Buffalo, 1997). The Fastskin suits used in the present study have microscopic vortex generators and riblets to channel water flow and have been purported to reduce total drag by $7.5 \%$ (11); however, this claim has been questioned (11), and the $\mathrm{D}_{\mathrm{SF}}$ in the present study was either not changed (WA, WK) or increased (SA, SK). The absence of effectiveness of the protuberances tested to date may be due to their placement or size, as the thickness of the boundary layer and its location are not known.

Based on the data from this study, the SA and SK dragreducing suits reduce drag significantly, and the effect is large enough to have an effect on competitive swimming performance. The suits did not compromise the maximal velocity of the dive or turn. The drag while actually swimming (active drag) is significantly greater than passive drag, due to the changes in body position and density and movement of arms and legs changing the direction of flow over the vortex generators and riblets $(4,5,10,11,15)$. Previous studies have suggested that there is no reduction in active drag when wearing drag reduction suits (16). These authors report, however, that some swimmers did have a reduction in active drag $\left(21.66 \mathrm{v}^{2.23}\right)$ compared with a competition suit $\left(23.32 \mathrm{v}^{2.29}\right)$ which represents an $11 \%$ reduction at 1.65 $\mathrm{m} \cdot \mathrm{s}^{-1}$. It is unclear what the differences in the subjects that had a reduction in drag and those that did not were, if any. The system used to determine drag in these studies requires the swimmer to use only arms, with the legs floated which alters active drag and perhaps the effects of the suits.

It has been shown that shaving body hair reduces the energy cost of swimming, presumably due to reduced $\mathrm{D}_{\mathrm{SF}}$, (13) and in this case the suits may not provide any additional benefit (11). The present study used unshaven swimmers; however, the $C_{D}$ of shaved swimmers determined by the methods used in this study reduced the $C_{D}$ of the same shaved swimmers from 0.58 to 0.53 (9\%), which is less than the effects of the suits (15\%) and previously shown by the same group for a torso suit (14). Additional details are given in the thesis, Oppenheim, E. Model parameter and drag coefficient estimation from swimmer velocity measurements (M.S. Thesis, Department of Mechanical Engineering, University at Buffalo, 1997).

It is clear that loose fitting competition or drag-reducing suits can increase drag when compared with tight-fitting suits $(16 ; 17)$. We compared a competition suit with a training suit, using the system described above, and found a $\mathrm{C}_{\mathrm{D}}$ of 1.04 and 1.29 , respectively. The data clearly suggests that both types of suits should be tight fitting.

In summary, the total passive drag determined in the presently reported study was significantly reduced by Fastskin suits that covered the swimmer from the shoulder to either the ankle or knee compared with models that covered only the lower body or a conventional suit. The data demonstrate that laminar flow undergoes transition-to-turbulence in the first few centimeters of the body (head) and that the flow is transitional over the rest of the body. Con- 
trary to common beliefs, the $\mathrm{D}_{\mathrm{SF}}$ is increased by these suits, and the data are consistent with the concept that the increased friction on the shoulders caused by the suit, trips the boundary layer, causing attachment of flow to the body, and results in reduced pressure, wave and total drag. It seems that at least in some swimmers, the active drag is also reduced (16). Based on these data, suits that cover from the shoulder reduce drag and may improve performance, but only for velocities above $1.5 \mathrm{~m} \cdot \mathrm{s}^{-1}$. Below $1.5 \mathrm{~m} \cdot \mathrm{s}^{-1}$, no differences were observed. Changing the characteristic of flow around the head of a swimmer and effective use of protuberances in strategic locations on the body needs further study as does the implications for these passive drag

\section{REFERENCES}

1. Chatard, J. C., J. M. Lavoie, B. Bourgoin, and J. R. Lacour. The contribution of passive drag as a determinant of swimming performance. Int. J. Sports Med. 11:367-372, 1990.

2. Cooper, R. D., and M. P. Tulin. The laminar flow about very slender cylinders in axial motion, including the effect of pressure gradients and unsteady motions. David Taylor Model Basin Report 838:1-35, 1953.

3. Craig, A. B., JR., and D. R. Pendergast. Relationships of stroke rate, distance per stroke, and velocity in competitive swimming. Med. Sci. Sports Exerc. 11:278-283, 1979.

4. Di Prampero, P. E., D. R. Pendergast, D. R. Willon, and D. W. RenNiE. Body drag and efficiency in swimming. Arch. Fisiol. 69(Suppl.):502-515, 1972.

5. Di Prampero, P. E., D. R. Pendergast, D. R. Wilson, and D. W. ReNNIE. Energetics of swimming in man. J. Appl. Physiol. 37:1-5, 1974.

6. ECKERT, H. U. Simplified treatment of the turbulent boundary layer along a cylinder in compressible flow. J. Aeron. Sci. 19:23-28, 1952.

7. Fox, R. W., and A. T. McDonald. Introduction to Fluid Mechanics, 4th Ed. New York: John Wiley \& Sons, 1992, p. 440.

8. LANDweber, L. The axially symmetric potential flow about elongated bodies of revolution. David Taylor Model Basin Report 761:1-65, 1949.

9. McLean, S. P., and R. N. HinRichs. Sex differences in the center of buoyancy location of competitive swimmers. J. Sport Sci. 16:373-383, 1998.

10. Pendergast, D. R., P. E. Di Prampero, A. B. Craig, Jr., D. R. WILson, and D. W. RenNIE. Quantitative analysis of the front crawl in men and women. J. Appl. Physiol. Respirat. Environ. Exerc. Physiol. 43:475-479, 1977. studies on active drag and performance. Nevertheless, decomposing total drag, into $\mathrm{D}_{\mathrm{SF}}, \mathrm{D}_{\mathrm{P}}$ and $\mathrm{D}_{\mathrm{W}}$ is believed to be helpful in understanding the physical mechanisms that determine drag.

We thank Adolph Kiefer and Associates for their data on swimming suit use and the University at Buffalo Swimming and Diving Team for their participation. We acknowledge the technical assistance of Dean Marky, Frank Modlich, Eric Stimson, and Michael Fletcher.

The authors gratefully acknowledge support for this research from the United States Navy, NAVSEA, Navy Experimental Diving Unit, contract N6133199C0028.

No funding or support was given by the swimming suit manufacturer or supplier.

11. Sanders, R., B. Rushall, H. Toussaint, J. Stager, and H. Takagi Bodysuit yourself, but first think about it. Am. Swimming Magazine 5:23-32, 2001.

12. Sсhмiтt, T. J. Wind-tunnel investigation of air loads on human beings. David Taylor Model Basin Report 892:1-65, 1954.

13. Sharp, R. L., and D. L. CostiLl. Influence of body hair removal on physiological responses during breaststroke swimming. Med. Sci. Sports Exerc. 21:576-80, 1998.

14. Starling, R. D., D. L. Costill, T. A. Trappe, A. C. Jozsi, S. W. Trappe, and B. H. GoOdPlaster. Effect of swimming suit design on the energy demands of swimming. Med. Sci. Sports Exerc. 27:1086-1089, 1995.

15. Toussaint, H. M., D. de Groot, H. H. C. M. Savelberg, K. Vervoorn, A. P. Hollander, and G. J. van Ingen Schenau. Effect of a triathlon wet suit on drag during swimming. Med. Sci. Sports Exerc. 21:325-328, 1989.

16. Toussaint, H. M., M. Truijens, M. J. Elzinga, et al. Effect of a Fast-skin "body" suit on drag during front crawl swimming. Sport Biomech. 1:1-10, 2002.

17. Walsh, J. Suits slicker than skin. Swim Magazine July:1-4, 1998.

18. Zamparo, P., G. Antonutto, C. CAPelli, et al. Effects of body size, body density, gender and growth on underwater torque. Scand. J. Med. Sci. Sports 6:273-280, 1996.

19. Zamparo, P., C. Capelli, B. Termin, D. R. Pendergast, and P. E Di PRAMPERO. Effect of the underwater torque on the energy cost, drag and efficiency of front crawl swimming. Eur. J. Appl. Physiol. 73:195-201, 1996.

20. Zatsionsky, M. (Ed.). Biomechanics in Sport: Performance Improvement and Injury Prevention. Boston: Blackwell Science, 2000, pp. 184-231. 